\title{
Prevalence and Incidence of Urinary Incontinence in Community-Dwelling Populations
}

A. Regula Herzog, PhD, and Nancy H. Fultz, MA

$\mathrm{P}$ revalence and incidence represent important characteristics of urinary incontinence as it appears in the population. Prevalence estimates provide an indication of how widespread involuntary urine loss is and have important implications for the level of medical and self-care that is needed. Incidence estimates provide an indication of the onset of the condition and are critical when studying its development, risk factors, and sequelae.

Early estimates of prevalence of incontinence in the community came almost exclusively from European studies. Several reviews of these studies are available., The reviews point out that prevalence estimates vary, and they suggest that differences in the definition of incontinence and in the sample account for much of the variability. More recently, several prevalence estimates have become available from regional or national US samples that had not been previously reviewed nor, in several instances, been formally published. This article compiles prevalence and incidence estimates from American and non-American studies published or conducted since 1970 . These studies used survey respondents' reports of involuntary urine loss to measure prevalence and, in some cases, incidence and symptoms of types of urinary incontinence. Some estimates had to be calculated from reported or computerized data. Because information regarding study design and measurement was incomplete for some of the studies, the estimates must be taken as close approximations only. Further details about the reestimation procedures are given in the Appendix.

From the Institute of Gerontology and Institute for Social Research, The University of Michigan, Ann Arbor, Michigan.

Partially supported by Grant No. P01 AGO3742 from the National Institute on Aging, Baltimore, Maryland.

Prepared for the National Institutes of Health Consensus Development Conference on Urinary Incontinence in Adults, Bethesda, Maryland, October 3-5, 1988.

Address correspondence and reprint requests to A. Regula Herzog, PhD, Associate Research Scientist, Institute for Social Research, P.O. Box 1248, The University of Michigan, Ann Arbor, MI 48106-1248.

\section{DEFINITION OF PREVALENCE AND INCIDENCE}

Prevalence of urinary incontinence is defined as the probability of being incontinent; it is estimated by the number of incontinent persons divided by the total number of examined persons. Incidence is defined as the probability of becoming incontinent during a defined period of time, given continence at the onset of the time period. It is estimated by dividing the number of incontinent persons (who were continent at the onset of the time period) by the total number of continent persons at onset.

\section{SOURCE OF DATA}

Components of prevalence and incidence estimates can be obtained from surveys of the population or, more typically, from sample surveys representing the population to which generalizations are to be made. In order for the information to be accurate, quality aspects of the data source are critical. In terms of the sample, a proper sampling frame of the target population has to be used, a large enough sample has to be drawn properly from the sampling frame, the sampled persons should participate in the survey, and, if some do not participate, appropriate adjustments should be made for any systematic differences between respondents and nonrespondents. If some of these conditions are not met, unreliability and/ or bias may be introduced into the rates.

Relevant surveys are typically conducted as personal interviews or sometimes as mail questionnaires that collect self-reported data rather than clinical or urodynamic information. Systematic bias as well as unreliability may be introduced during the process of responding to the survey if questions are not asked in an appropriate way or are not properly introduced, if response scales are not appropriate, or if the definition of incontinence underlying the questions is inaccurate. Although the significance of these data quality issues has generally been recognized by researchers working on urinary incontinence, little rigorous information is available to assure the quality of the data with which we work. In 
order to provide the context within which to evaluate the information on prevalence and incidence, the quality of survey information on urinary incontinence will be briefly reviewed.

In terms of sample and nonresponse issues, many of the earlier surveys took their samples from lists of patients. Unless such lists include all persons in the population, they are unsuitable sampling frames. Further, even rigorous sample surveys of older age groups sometimes encounter difficulties in recruiting all sampled persons for an interview, a fact that is reflected in relatively low response rates. ${ }^{3}$

Although efforts are typically made to maximize the response rate, evaluating the characteristics of nonrespondents and assessing possible bias are a necessity for any serious survey. We conducted an assessment of nonresponse and attrition in a sample survey of urinary incontinence among persons 60 years of age and older in Washtenaw County, Michigan (Medical, Epidemiologic, and Social Aspects of Aging [MESA] study).4 The findings show that women over 75 were less likely to participate in the original survey than were those under 75 , and that women over 75 dropped out of the two follow-up surveys at higher rates. Self-reported continence was also related to attrition among women. Poor health was associated with an increased likelihood of dropping out among men. Urinary phenomena were also related to study participation in a sample of patients in England who were selected for a health examination study: women with urinary tract infection were more likely to participate than those without the condition. ${ }^{5}$ In sum, incontinent persons may be more likely to participate or remain in a study than continent persons.

These findings raise the possibility that prevalence and incidence rates resulting from sample surveys are biased. In the MESA study we adjusted prevalence and incidence estimates for the observed nonresponse patterns and did not produce figures that differed greatly from unadjusted figures. ${ }^{4}$

In terms of potential errors introduced during the interview, several aspects must be mentioned. The definition that underlies the questions about incontinence is obviously critical. Although most recent studies attempt to measure actual loss of urine and to include symptoms of stress as well as urge and mixed types of incontinence, some studies still phrase questions in a manner that captures mostly urge-type loss and/or that does not assess whether actual loss occurred. Examples include the question in the Older Americans Resources and Services (OARS) instrument" "Do you ever have trouble getting to the bathroom on time?" and the question used in all Established Populations for Epidemiologic Studies of the Elderly (EPESE) studies" "How often do you have difficulty holding your urine until you can get to a toilet?" Other problems related to the definition have to do with the specification of the reference period (eg, "now," "during the past 12 months," "ever") and with the specification of the severity of the condition (eg, frequency, quantity).

Reliability and validity are standard criteria of measurement quality for survey questions and instruments. Reliability refers to the degree to which measurements are repeatable at different times, by different investigators, or with different measures of the same attribute. In order to test its reliability, a survey question that is very similar to the one used in the MESA survey was asked at the beginning and the end of an interview with an adult sample in Detroit. ${ }^{8}$ Overall agreement of responses reporting any incontinence was $97 \%$ (Table 1). On the other hand, in a small sample of elderly people who were reinterviewed after two months, a relatively low agreement rate was observed.9

Reliability is a necessary but not a sufficient condition for measurement quality. A measure can be entirely reliable and yet be terribly biased. Reporting of incontinence is likely to be biased because embarrassing information tends to be underreported, ${ }^{10}$ and incontinence is viewed as an embarrassing condition. ${ }^{11}$ In the MESA study we made an effort to validate self-reports of incontinence by comparing them to diagnoses based on clinical examinations, in which a subset of 754 respondents participated about three to 12 months after the survey interview at the University of Michigan Medical Center. (The subset of survey respondents who agreed to participate in the clinical examination was somewhat younger and healthier than those who did not partici-

TABLE 1. SELF-REPORT AT THE BEGINNING AND THE END OF THE INTERVIEW, FOR PERSONS AGED 63 AND OVER

\begin{tabular}{|c|c|c|c|}
\hline & \multicolumn{2}{|c|}{ Early Question } & \multirow{2}{*}{$\begin{array}{l}\text { \% Agreement with } \\
\text { Late Question }\end{array}$} \\
\hline & Continent & Incontinent & \\
\hline \multicolumn{4}{|l|}{ Late question } \\
\hline Continent & 631 & 4 & 99.4 \\
\hline Incontinent & 20 & 126 & 86.1 \\
\hline$\%$ Agreement with early question & 96.9 & 97.1 & \\
\hline
\end{tabular}

Note: Entries are weighted frequencies.

Source: Michigan Generations Follow-up, 1987. 
pate.) The clinical exam included a standardized history, physical examination, and a simple provocative stress test without invasive procedures. Overall, there was an $83 \%$ agreement between the self-reports and the clinician's assessment (Table 2 ).

This validation cannot be generalized to other studies, however, because in the MESA survey we made a special effort to reduce underreporting, an effort not made in most surveys dealing with incontinence. We prefaced the incontinence questions with an introduction that stated the importance of the information requested from the respondent and we followed each negative report with a probe. About $10 \%$ of all self-reported incontinent persons admitted to incontinent episodes only after the probe had been asked.

A study by Hilton and Stanton ${ }^{12}$ provides some information on the validity of self-reported stress and urge symptoms. Stress symptoms were more frequently reported by women who were diagnosed as having sphincter incompetency than by those diagnosed with detrusor instability, whereas urge symptoms were more frequently reported by those with detrusor instability. However, the correspondence was by no means perfect. Reasonably high correspondence between self-reported stress symptoms and urodynamically determined diagnosis of stress incontinence was also obtained by Diokno et al. ${ }^{13}$

To summarize, the quality of the measurement of urinary incontinence is not well established, and the few studies that have addressed the issue paint an uneven picture. Additional work to establish reliability and validity of incontinence survey measures is needed. Yet the appropriate validation criterion is not clear because some types of incontinence cannot reliably be reproduced in the clinical examination.

\section{REVIEW OF EXISTING PREVALENCE ESTIMATES}

Prevalence of Any Involuntary Urine Loss Among Older Adults Studies reporting prevalence figures for any urine loss or urine control problem among older adults are shown in Table 3 . All of the studies conducted in the 1970s and a few of those conducted in the 1980s were not conducted in the United States, and most of them report on patients sampled from registries of medical practices. ${ }^{14-19}$ Many of these studies show a prevalence between $12 \%$ and $15 \%$, but one goes as high as $34 \%$.

More recently, two sample surveys of American households suggest higher prevalences, including a prevalence of $33 \%$ percent in the National Health and Nutrition Examination Survey (NHANES) Follow-Up (estimate was based on analysis of a preliminary set of NHANES data) conducted in the early $1980 \mathrm{~s},{ }^{20}$ and of $30 \%$ in the MESA survey conducted in 1983-1984. ${ }^{21}$ Four other American sample surveys, however, show lower estimates than these just mentioned, in the range of $10 \%$ to $20 \%$. They include the East Boston Senior Health Project (EBSHP), ${ }^{22}$ the 1984 Supplement on Aging (SOA), ${ }^{23}$ the 1986 Americans' Changing Lives (ACL) study, ${ }^{24}$ and the 1987 Michigan Generations (MGS) Follow-Up Study. ${ }^{8}$ More information about sources of unpublished estimates is included in the Appendix.

All the studies reviewed here were aimed at older adults (usually defined as $60+$ or $65+$ ) living in the community. In a very few studies the age cut-off was defined differently, and in a few studies institutionalized persons were also included. The household samples utilized in the American surveys may provide better

TABLE 2. SELF-REPORT IN SURVEY AND DIAGNOSIS FROM CLINICAL EXAM, FOR PERSONS AGED 60 AND OVER

\begin{tabular}{lccc}
\hline & \multicolumn{2}{c}{ Clinical Diagnosis } & \% Agreement with \\
\cline { 2 - 3 } & Continent & Incontinent & \\
\hline Female & & & \\
Self-report & 215 & 43 & 83.3 \\
$\quad$ Continent & 32 & 166 & 83.1 \\
$\quad$ Incontinent & 86.5 & 79.2 & \\
\% Agreement with diagnosis & & & \\
Male & 199 & 15 & 92.8 \\
Self-report & 36 & 48 & 56.0 \\
$\quad$ Continent & 84.6 & 75.9 & \\
Incontinent & & & \\
\% Agreement with diagnosis &
\end{tabular}

Note: Entries are unweighted frequencies. The percentages are based on weighted frequencies.

Source: MESA, 1984. 
TABLE 3. PREVALENCE OF ANY URINARY INCONTINENCE AMONG OLDER PERSONS, BY STUDY

\begin{tabular}{|c|c|}
\hline Study & $\%$ Prevalence \\
\hline Supplement on Aging, $1984^{23}$ & 8 \\
\hline$A C L, 1986^{24}$ & 9 \\
\hline McGrother et al, $1986^{14}$ & 11 \\
\hline Campbell et al, $1985^{15}$ & 12 \\
\hline EBSHP, $1986^{22}$ & 13 \\
\hline Vetter et al, $1981^{16}$ & 14 \\
\hline Yarnell and St. Leger, $1979^{17}$ & 16 \\
\hline Michigan Generations Follow-Up, $1987^{8}$ & 17 \\
\hline Thomas et al, $1980^{18}$ & 23 \\
\hline MESA, $1986^{21}$ & 30 \\
\hline NHANES Follow-Up, $1986^{20}$ & 33 \\
\hline Milne et al, $1972^{19}$ & 34 \\
\hline
\end{tabular}

coverage of the older population than the patient registries used in the other studies, although the National Health Care system in Great Britain - where most of the non-American studies were done - permits everybody to register with a doctor and would also be expected to provide relatively complete coverage, at least if all medical practices in the geographic region were to be used. On the other hand, the response rates obtained in the household samples were typically lower than those in the samples from the registries. At any rate, sample characteristics do not seem to provide an obvious explanation for the observed variation in prevalence estimates because household samples produced some of the highest and also some of the lowest estimates.

The American and non-American studies probed for any incontinence episodes at all, and many were intended to capture all types of urinary incontinence either by focusing on the actual loss or by specifying the circumstances of the loss. However, some studies appear to elicit information predominantly about the urge type of incontinence or urgency by asking about "difficulties in controlling urine," "difficulty holding urine until you can get to the toilet," etc. But again, the differences in definition of urinary incontinence do not appear to explain the variation in estimates: the all-type measures produced both some of the higher and also some of the lower estimates.

Although it is always difficult to pinpoint the critical difference between studies that differ in several aspects at the same time, it is conceivable that underreporting provides part of the explanation for the differences between the first and the second set of American studies. Because of the embarrassment of disclosing one's incontinence, the condition is likely to be underreported unless the interview is carefully designed to acknowledge the embarrassing nature of the topic and to highlight the importance of accurate information. Such procedures were used in the MESA study, which shows a high prevalence estimate, whereas in the ACL and the SOA studies, which yielded rather low estimates, the questions about incontinence were mixed in with batteries of other questions. No mention was made of the importance of providing accurate data on incontinence, nor was the difficulty of talking about urinary incontinence symptoms explicitly acknowledged. Future research should pay more attention to the possibility of underreporting.

To summarize, considerable variation in the prevalence estimates of any urinary incontinence is observed, and no entirely satisfactory explanation of the variation is presently available. Nevertheless, everything else being equal, the higher figures are probably the more accurate ones because cognitive problems associated with forgetting and motivational problems associated with the embarrassing nature of the condition would both tend to produce underreporting. Thus, a $30 \%$ prevalence of any urine loss during a 12-month period is a plausible estimate. This is the figure observed in the MESA study, ${ }^{21}$ which used measures that obtained a satisfactory validity and test-retest reliability.

Prevalence of Any Loss Among Younger Ages Fewer studies have examined incontinence in young adults, and the populations studied differ considerably. Consequently, the prevalence figures are not very consistent. Rather than try to compare this subset of prevalence figures directly to the figures for older adults - a comparison that is confounded by differences between the studies included - four studies are discussed that treat the entire age range and provide age-specific rates (Table 4). These studies demonstrate that within the adult age range, prevalence figures for any urine loss increase with increasing age by a factor of two or more. The Yarnell et al study, ${ }^{25}$ which shows the smallest age difference, includes only women. Because women more frequently have stress incontinence that does not increase with age, this might explain the relatively small

TABLE 4. AGE DIFFERENCES IN PREVALENCE OF ANY URINARY INCONTINENCE, BY STUDY

\begin{tabular}{lc}
\hline \multicolumn{1}{c}{ Study } & $\%$ Prevalence \\
\hline ACL, $1986^{24}$ & \\
$25-59$ years old & 2 \\
$60+$ years old & 9 \\
Michigan Generations Follow-Up, $1987^{8}$ & \\
23-62 years old & 8 \\
$63+$ years old & 17 \\
Thomas et al, $1980^{18}$ & \\
$25-64$ years old & 18 \\
65+ years old & 23 \\
Yarnell et al, 1981 (women only) & \\
$25-64$ years old & 46 \\
65+ years old & 49 \\
\hline
\end{tabular}


difference as to urinary incontinence between age groups. Given the prevalence of about $30 \%$ estimated above for older adults, and a certain increase in prevalence from younger to older adults, a minimum prevalence of $10 \%$ to $15 \%$ among the 20 - to 60 -year-old adults seems a reasonable estimate.

Several studies have examined age differences within the older population, but they present inconsistent findings. Several of the reviewed studies report a relationship between incontinence and age for both older men and older women, ${ }^{16,17,22,26}$ whereas others noted it only among older men. ${ }^{18,20}$ Finally, no significant relationship between incontinence and age was found for either sex in two studies. ${ }^{19,21}$

Prevalence of Severe Loss of Urine The International Continence Society defines urinary incontinence as involuntary loss "which is a social or hygienic problem." ${ }^{27}$ This definition implies a certain severity of the condition, rather than any incontinence. Severity has been operationalized in different ways in the available studies, but most often by reference to frequency of episodes of loss, varying from "daily" to "weekly" to "about once or twice a month." In none of the studies has the severity measure been validated.

The prevalence of severe urinary incontinence (where severe is defined as frequency of loss of "weekly" or more often, "regularly," or "most of the time") is lower than the overall prevalence. More interesting, however, is the fact that prevalence estimates for severe incontinence are more consistent across studies than are those for any loss. They range between $3 \%$ and $11 \%$, with the majority between $4 \%$ and $6 \%$ (Table 5 ). One might speculate that severe urine loss is more obvious to the respondent and cannot be as easily denied. As a consequence, the reporting of severe incontinence is probably less dependent on question wording and context than is the reporting of mild incontinence, and the resulting prevalence rates are more consistent across studies.

TABLE 5. PREVALENCE OF SEVERE URINARY INCONTINENCE AMONG OLDER PERSONS, BY STUDY

\begin{tabular}{|c|c|}
\hline Study & $\%$ Prevalence \\
\hline Campbell et al, $1985^{15}$ & 3 \\
\hline NHANES Follow-Up, $1986^{20}$ & 4 \\
\hline MESA, $1986^{21}$ & 4 \\
\hline Michigan Generations Follow-Up, 1987 $^{\circ}$ & 4 \\
\hline Milne et al, $1972^{19}$ & 5 \\
\hline Vetter et al, $1981^{16}$ & 5 \\
\hline Supplement on Aging $1984^{23}$ & 6 \\
\hline EBSHP, $1986^{22}$ & 7 \\
\hline Thomas et al, $1980^{18}$ & 10 \\
\hline Yarnell and St Leger, $1979^{17}$ & 11 \\
\hline
\end{tabular}

Prevalence estimates for severe urinary incontinence increase from young and middle age to older age in a manner similar to prevalences of any urine loss, although the small number of studies - the Michigan Generations Follow- $U \mathrm{p}^{8}$ and the Thomas et al ${ }^{18}$ studies - suggests caution in interpretation.

Future work should expand the definition of severe incontinence. In the MESA study we not only measured frequency but also quantity of loss. Cross-classification showed that the two criteria, although related, were not redundant. ${ }^{21}$ Whereas some respondents reported high frequency and high quantity, others reported high frequency and low quantity, and still others reported low frequency and high quantity. Similar results were obtained by the EBSHP. ${ }^{22}$

Another aspect that might be included in the definition of severity is the subjective assessment. Wyman and colleagues ${ }^{28}$ measured the subjective impact of incontinence along with objective frequency, and observed only a modest relationship between the two. This suggests that the subjective assessment captures yet another dimension of severity. These findings indicate that we should not focus on the frequency of urine loss alone but should rather consider several criteria of severity.

Prevalence of Symptoms of Stress and Urge Incontinence Among Older Adults Among the different types of incontinence, symptoms of stress incontinence can be differentiated relatively easily in a personal interview by asking about the circumstances in which urine is lost. Stress incontinence is indicated by urine loss during activities that cause a sudden increase in intraabdominal pressure (eg, running, jumping, and lifting heavy objects). Five studies asked questions phrased to measure symptoms of stress incontinence. One should note that most of these studies reported a relatively high prevalence of any incontinence and had not validated the stress measure. The estimates for simple stress incontinence range from $3 \%$ to $20 \%$ (Table 6), and represent about one-quarter to one-third of all incontinence cases. The Milne et al study, which has the highest estimates, did not measure combined stress and

TABLE 6. PREVALENCE OF TYPES OF URINARY INCONTINENCE AMONG OLDER PERSONS, BY STUDY

\begin{tabular}{lccr}
\hline & \multicolumn{3}{c}{ \% Prevalence } \\
\cline { 2 - 4 } \multicolumn{1}{c}{ Study } & Stress & Urge & Both \\
\hline EBSHP, 198829* & 3 & 5 & 3 \\
MESA, 1986' & 7 & 5 & 15 \\
NHANES Follow-Up, 1986 $^{20}$ & 16 & & \\
Milne et al, 1972 $^{19}$ & 20 & 21 & \\
\hline
\end{tabular}

- Only incontinent respondents who lose urine once a month or more often were categorized into types. 
urge symptoms separately; therefore, its estimates must contain cases of combined stress and urge symptoms.

Urge-type incontinence is typically operationalized in personal interviews by as yet unvalidated questions probing the uncontrollable need to void and the difficulty of getting to the bathroom in time; often actual loss is not probed, and thus the symptom might be more properly labeled "urgency." The studies that use defensible measures of loss ${ }^{19,21,29}$ show figures ranging from $5 \%$ to $21 \%$. The same comment made before about the Milne et al study applies here.

About an equally large proportion of all older adults report urge in combination with stress symptoms, as indicated in the MESA ${ }^{21}$ and the EBSHP ${ }^{29}$ studies (Table 6).

Sex Differences in Urinary Incontinence Sex differences in the prevalence of urinary incontinence are observed in almost all studies that have examined them (Table 7). Among adults over 60 , women usually have a likelihood of urinary incontinence at least twice as high as that of men. Interestingly, among adults under $\mathbf{6 0}$ years of age, the sex difference appears even more pronounced. The few studies that permit an examination of the sex difference at different age levels show younger women's prevalence figures to be at least three times higher than those for younger men (Table 8).

Several studies permit the examination of sex differences for prevalence of severe incontinence among the elderly. These sex differences do not seem to be distinctly different from those for any incontinence. Estimates for older women tend to be about twice as high as those for older men (Table 9).

Finally, Table 10 displays data indicating that symptoms of stress incontinence are much more prevalent among older women than among older men. The MESA study ${ }^{21}$ and the EBSHP ${ }^{29}$ further indicate that combined incontinence is more prevalent among older women than older men.

\section{TABLE 7. SEX DIFFERENCES IN ANY URINARY INCONTINENCE AMONG OLDER PERSONS, BY STUDY}

\begin{tabular}{|c|c|c|}
\hline \multirow[b]{2}{*}{ Study } & \multicolumn{2}{|c|}{$\%$ Prevalence } \\
\hline & Men & Women \\
\hline Supplement on Aging, $1984^{23}$ & 7 & 9 \\
\hline Yarnell and St Leger, $1979^{17}$ & 11 & 17 \\
\hline ACL, $1986^{24}$ & 6 & 12 \\
\hline EBSHP, $1986^{22}$ & 8 & 16 \\
\hline Thomas et al, $1980^{18}$ & 16 & 27 \\
\hline Vetter et al, $1981^{16}$ & 7 & 18 \\
\hline Michigan Generations Follow-Up, $1987^{8}$ & 11 & 23 \\
\hline Milne et al, $1972^{19}$ & 25 & 42 \\
\hline MESA, $1986^{21}$ & 19 & 38 \\
\hline NHANES Follow-Up, $1986^{20}$ & 20 & 42 \\
\hline
\end{tabular}

TABLE 8. SEX DIFFERENCES IN ANY URINARY INCONTINENCE, BY AGE GROUPS, BY STUDY

\begin{tabular}{lrr}
\multicolumn{1}{c}{ Study } & \multicolumn{2}{c}{$\%$ Prevalence } \\
\cline { 2 - 3 } & Men & Women \\
\hline ACL, 1986 & & \\
25-59 years old & 1 & 4 \\
60+ years old & 6 & 12 \\
Michigan Generations Follow-Up, 1987 & & \\
23-62 years old & 2 & 12 \\
63+ years old & 11 & 23 \\
Thomas et al, 1980 \\
25-64 years old \\
65+ years old
\end{tabular}

\section{INCIDENCE OF URINARY INCONTINENCE}

Very little information about the incidence of urinary incontinence is currently available. A study of people aged 65 and over living in the community and institutions in New Zealand suggests that about $10 \%$ of originally continent adults develop urinary incontinence over a three-year period. ${ }^{15}$ One-year incidence rates of $10 \%$ for older men and $20 \%$ for older women were observed in the MESA study. ${ }^{30}$ The second estimate is much higher than the first, which parallels the difference in prevalence between the two studies. We are cautiously optimistic about the MESA data because of the evidence regarding reliability and validity of measurement and because of our inability to identify any major attrition bias. Confirmation of these findings would, however, be desirable.

These and two additional studies ${ }^{17,18}$ further document that as much as a third of incontinent respondents become continent over time. The latter observation raises the more general question about the course of urinary incontinence over time. Currently we do not know what proportion of community-residing incontinent cases take a chronic course and what proportion are transient. Nor do we know whether the chronic

\section{TABLE 9. SEX DIFFERENCES IN SEVERE URINARY INCONTINENCE AMONG OLDER PERSONS, BY STUDY}

\begin{tabular}{|c|c|c|}
\hline \multirow[b]{2}{*}{ Study } & \multicolumn{2}{|c|}{$\%$ Prevalence } \\
\hline & Men & Women \\
\hline Milne et al, $1972^{19}$ & 5 & 4 \\
\hline NHANES Follow-Up, $1986^{20}$ & 3 & 5 \\
\hline Supplement on Aging, $1984^{23}$ & 5 & 7 \\
\hline Michigan Generations Follow-Up, $1987^{8}$ & 3 & 5 \\
\hline MESA, $\mathbf{1 9 8 6}^{21}$ & 2 & 6 \\
\hline EBSHP, $1986^{22}$ & 5 & 9 \\
\hline Thomas et al, $1980^{18}$ & 7 & 12 \\
\hline Feneley et al, $1979^{26}$ & 6 & 14 \\
\hline
\end{tabular}


TABLE 10. SEX DIFFERENCES IN PREVALENCE OF TYPES OF URINARY INCONTINENCE AMONG OLDER PERSONS, BY STUDY

\begin{tabular}{|c|c|c|c|}
\hline \multirow[b]{2}{*}{ Stu } & \multicolumn{3}{|c|}{$\%$ Prevalence } \\
\hline & Stress & Urge & Both \\
\hline \multicolumn{4}{|c|}{ EBSHP, $1988^{29 *}$} \\
\hline Men & $<1$ & 5 & 1 \\
\hline Women & 5 & 6 & 4 \\
\hline \multicolumn{4}{|c|}{ MESA, 1986 21} \\
\hline Men & 1 & 7 & 5 \\
\hline Women & 10 & 3 & 21 \\
\hline \multicolumn{4}{|c|}{ Milne et al, $1972^{19}$} \\
\hline Men & 6 & 21 & \\
\hline Women & 31 & 21 & \\
\hline \multicolumn{4}{|c|}{ Yarnell et al, $1981^{25} \dagger$} \\
\hline Women & 17 & 13 & 19 \\
\hline \multicolumn{4}{|c|}{ NHANES Follow-Up, $1986^{20}$} \\
\hline Men & 6 & & \\
\hline Women & 23 & & \\
\hline
\end{tabular}

- Only incontinent respondents who lose urine once a month or more were categorized into types.

†Yarnell et al studied women only.

progression is from mild to more severe incontinence and/or from a simple type to combined symptoms. We do not know what risk factors lead to one or another progression, and we do not know the outcomes of these progressions. Knowledge about the course of incontinence and the relevant risk factors is critical for prevention and for planning intervention strategies. All of these questions require survey information collected over time. Attention to the possibilities of differential attrition and unreliability or of stable underreporting bias is particularly critical in longitudinal investigations because they can create the false impression of change or stability.

\section{SUMMARY AND DISCUSSION}

The prevalence of any urinary incontinence among older adults living in the community is likely to be as high as $30 \%$ - an impressive figure. The prevalence of weekly (or more frequent) urine loss is more modest $5 \%$. A higher figure for severe loss might be obtained if a more comprehensive definition of severity were used. Prevalence figures are necessary for understanding the extent of the condition and for calculating the costs associated with it. In this context, the suspicion that some estimates reflect substantial underreporting is particularly worrisome.

Our trust in these estimates must be somewhat compromised when we consider the variability in the figures. The absence of standardized and well validated measures of mild and severe urinary incontinence is deplorable. Future work should address aspects of measurement quality more forcefully.
Even less information is currently available on the prevalence of particular types of incontinence and on the quality of the relevant self-report measures. Age and sex patterns, risk factors, and the course of progression for stress, urge, and complex incontinence are probably quite different. Differentiation of incontinence by types and the development of appropriate measures should be a high priority of future epidemiologic research. The first data of this type of which we are aware were presented at a recent conference. ${ }^{29}$

Because studies have shown that about half of all incontinent persons have never talked to a physician about their condition, ${ }^{31}$ a reliance on representative sample surveys for establishing prevalence estimates is absolutely essential. Clinical populations most likely represent a select group of incontinent persons, and one should not rely on them to yield accurate figures.

The prevalence figures for any and for severe incontinence are lower for persons under 60 , but they are not zero! In other words, incontinence is not uniquely a problem of older adults, but can also occur among those in their middle years. There is some suggestion that incontinence in the middle years affects primarily women in the form of stress incontinence.

The estimates for men and women differ considerably, with women more likely to be incontinent. Only a few of the available studies disaggregated their estimates sufficiently, so that age and sex patterns of the different types of incontinence can be examined; this leaves another fruitful area for future research.

Although prevalence figures are suitable for projecting the level of need for medical and nonmedical care, incidence information from longitudinal studies is needed so that we may formulate treatment and prevention strategies. The onset and patterns of progression of incontinence, the factors related to the onset and progression, and the consequences of the onset and progression must be investigated. Few data are available, but two studies suggest a $10 \%$ to $15 \%$ incidence rate over a one-year period. ${ }^{15,30}$

The suggestion that as much as a third of all geriatric incontinence may be transient is also provocative. Implications for treatment will differ depending on the likely progression of incontinence. An aggressive treatment program might be advocated for mild incontinence if it turns out that all or most of such incontinence eventually becomes more severe. However, such a treatment program would be ill-advised if much of mild incontinence resolves by itself. The identification of possible risk factors for transient or progressive incontinence would permit closer targeting of those individuals who are at risk for more severe incontinence. For this purpose, too, samples should be representative of the general population rather than clinical groups. Very few longitudinal studies of community residents exist. They should receive very high research priority if we hope to 
understand, treat, and prevent urinary incontinence in the general public.

\section{ACKNOWLEDGMENTS}

The authors thank Morton Brown, Ananias Diokno, Willard Rogers, and Nancy Whitelaw for comments on earlier drafts of this paper.

\section{REFERENCES}

1. Milne JS: Prevalence of incontinence in the elderly age groups, in Willington FL (ed): Incontinence in the Elderly. London, Academic Press, 1976, p 9

2. Mohide EA: The prevalence and scope of urinary incontinence. Clin Geriatr Med 2:639, 1986

3. Herzog AR, Rodgers WL: Age and response rates to interview sample surveys. J Gerontol Soc Sci 43:S200, 1988

4. Brown MB, Lin DY, Normolle DP, et al: Models for and the effect of nonresponse in a survey of the noninstitutionalized elderly. Proceedings of the Survey Research Section, American Statistical Association, New Orleans, Louisiana, August 1988

5. Milne JS, Maule MM, Williamson J: Method of sampling in a study of older people with a comparison of respondents and nonrespondents. Br J Prevent Soc Med 25:37, 1971

6. The Study of the Well-being of Older People in Cleveland Ohio, 1975 - 1976 [code book]. Ann Arbor, Michigan, Inter-university Consortium for Political and Social Research

7. White LR, Kohout F, Evans DA, et al: Related health problems, in Cornoni-Huntley J, Brock DB, Ostfeld AM, et al (eds), Established Populations for Epidemiologic Studies of the Elderly: Resource Databook. Washington, DC, National Institute on Aging, U.S. Department of Health and Human Services, 1986, pp 129165

8. Survey Research Center, The University of Michigan: Michigan Generations Follow-Up. Unpublished computerized data.

9. Milne JS, Hope K, Williamson J: Variability in replies to a questionnaire on symptoms of physical illness. J Chronic Dis 22:805, 1970

10. Cannell CF, Fisher G, Bakker T: Reporting of hospitalization in the Health Interview Survey. Health Statistics Series D, No. 4. U.S. Department of Health, Education and Welfare, Public Health Service, 1961

11. Herzog AR, Fultz NH: Urinary incontinence in the community: Prevalence, consequences, management, and beliefs. Top Geriatr Rehab 3:1, 1988

12. Hilton $P$, Stanton SL: Algorithmic method for assessing urinary incontinence in elderly women. Br Med J 282:940, 1981

13. Diokno AC, Normolle DP, Brown MB, et al: Urodynamic tests for female geriatric urinary incontinence. Urology (in press)

14. McGrother CW, Castleden CM, Duffin H, et al: Provision of services for incontinent elderly people at home. J Epidemiol 40:134, 1986

15. Campbell AJ, Reinken J, McCosh L: Incontinence in the elderly: prevalence and prognosis. Age Ageing 14:65, 1985

16. Vetter NJ, Jones DA, Victor CR: Urinary incontinence in the elderly at home. Lancet 2:1275, 1981

17. Yarnell JWG, St Leger AS: The prevalence, severity and factors associated with urinary incontinence in a random sample of the elderly. Age Ageing 8:81, 1979

18. Thomas TM, Plymat KR, Blannin J, et al: Prevalence of urinary incontinence. Br Med J 281:1243, 1980

19. Milne JS, Williamson J, Maule MM, et al: Urinary symptoms in older people. Mod Geriatr 2:198, 1972

20. Harris T, Guralnik J, Madans J: The National Health and Nutrition Survey I Follow-Up: prevalence and correlates of urinary incontinence in community dwelling elders. Paper presented at the 39th Annual Scientific Meeting of the Gerontological Society of America, Chicago, Illinois, November, 1986

21. Diokno AC, Brock BM, Brown MB, et al: Prevalence of urinary incontinence and other urological symptoms in the noninstitutionalized elderly. J Urol 136:1022, 1986

22. Resnick NM, Wetle TT, Scherr $P$, et al: Urinary incontinence in community dwelling elderly: prevalence and correlates. Proceedings of the 16th Annual Meeting of the International Continence Society, Boston, Massachusetts, 1986, pp 76-77

23. National Center for Health Statistics, United States Department of Health and Human Services: National Health Interview Survey: Longitudinal Study of Aging, 70 Years and Over, 1984-86. Unpublished computerized data

24. Survey Research Center, The University of Michigan: Americans' Changing Lives Study. Unpublished computerized data

25. Yarnell JWG, Voyle GJ, Richards CJ, et al: The prevalence and severity of urinary incontinence in women. J Epidemiol Community Health 35:71, 1981

26. Feneley RCL, Shepherd AM, Powell PH, et al: Urinary incontinence: prevalence and needs. Br J Urol 51:493, 1979

27. Bates P, Bradley WE, Glen E, et al: The standardization of terminology of lower urinary tract function. J Urol 121:551, 1979

28. Wyman JF, Harkins SW, Choi SC, et al: Psychosocial impact of urinary incontinence in women. Obstet Gynecol 70:378, 1987

29. Resnick NM, Wetle $T$, Scherr $P$, et al: The prevalence and implications of types of incontinence in community-dwelling elderly: a population-based study. Proceedings of the 18th Annual Meeting of the International Continence Society, Oslo, Norway, 1988, pp 204-205

30. Herzog AR, Diokno AC, Brown MB, et al: Two-year incidence, remission, and change patterns of urinary incontinence in noninstitutionalized older adults. J Gerontol Med Sci (in press)

31. Herzog AR, Fultz NH, Normolle DP, et al: Methods used to manage urinary incontinence by older adults in the community. J Am Geriatr Soc 37:339-347, 1989 


\section{APPENDIX}

Procedures Used to Reestimate Prevalence and Incidence Figures In order to obtain comparable estimates for all studies, we aggregated or disaggregated estimates where necessary, based on the information provided in the article, or, in a few studies, based on computerized data. In defining incontinence, we included catheterized persons. In defining severity, we chose the category that came closest to "weekly" or more often, to "regularly," or to "most of the time." In identifying the relevant population, we defined "older" as aged 60 or 65 and over, if at all possible. We also excluded institutionalized persons and proxy respondents where this was possible.

We did not have the necessary information (eg, sampling weights) to recalculate the estimates for all of the studies. In such cases we either dropped the estimates or, when the error appeared to be minor, proceeded with caution. For this reason, however, we present these estimates as approximations.

Study Information for Unpublished Data The MGS consists of a 1984 survey and a 1987 resurvey of 1,491 adult persons living in the Detroit metropolitan area; 1,013 of them were 60 years of age or older. The response rate among those over 59 was $56 \%$, the reinterview rate was $69 \%$.

The question on incontinence was included in the 1987 reinterview and was phrased in the following way: "During the last 12 months - that is, since last [January . . . May] - have you lost any amount of urine beyond your control?"

The ACL Survey used a multistage stratified area probability sample of persons 25 years of age or older and living in the coterminous United States. Blacks and persons over 60 were sampled at twice the rate of whites under 60 , in order to facilitate comparisons by age and race. A total of 3,617 respondents, 1,669 of whom were aged 60 and older, were interviewed in their homes by interviewers of the Survey Research Center, reflecting a response rate of $68 \%$. The interviews were conducted between May and October 1986.

The question on incontinence was part of a list of conditions and were phrased "Have you lost any amount of urine beyond your control during the last 12 months?"

The EBSHP - one of the EPESE studies - is a census of persons 65 and older living in East Boston, a geographically well-defined area of Boston. The population is made up of low- and middle-income working-class persons. An initial survey was conducted in 1982 with 3,812 persons, representing a response rate of $85 \%$.

The prevalence data were collected at the second annual telephone reinterview. Of the 3,447 original respondents alive at that time, $96 \%$ responded. They were asked how often during the last 12 months they had "leaked" or "lost control of" their urine ("almost every day, about once a week, less often than once a week, about once a month, less often than once a month, or never"). Urinary incontinence was defined as any leakage.

The NHANES 1 Follow-Up Study estimates were based on interviews with 10,523 of 14,407 original NHANES 1 respondents aged 25 to 74. NHANES respondents are selected using a national multistage stratified probability design. Of the 9,866 respondents to the urinary questions, 3,100 were 65 years of age or older. The three questions used to define continence groups were: (1) "During the past few months how often have you lost control over your urine?" (often, occasionally, never); (2) "How often do you dribble, leak, or lose urine when you laugh, strain, or cough?" (often, occasionally, never); and (3) “Do you dribble or leak urine only when you laugh, strain, or cough?" (yes, no).

The Supplement on Aging (SOA) to the 1984 Health Interview Survey (HIS) was designed to collect health-related information about older community residents. The sample for the SOA consists of 16,148 persons 55 years of age or older, selected from the U.S. civilian noninstitutionalized population using a multistage probability sampling process. A $93 \%$ response rate was obtained.

For this paper, we restricted the analyses to the 11,497 respondents who were 65 or older. Proxy respondents were included. The measures that we used to define incontinence asked "Do you have difficulty controlling urination" and "How frequently do you have this difficulty - daily, several times a week, once a week, or less than once a week?" 